\title{
Study on Processing of Accounting Information based on ERP System
}

\author{
Ma Qing \\ Shaanxi Technical College of Finance and Economics, Shaanxi, China, 712000
}

Keywords: ERP system; Accounting information; Measures

Abstract: With the rapid development of information technology and "Internet +", ERP system has gradually replaced the traditional enterprise management mode in enterprise management. The accounting industry has gradually followed the trend of the times and abandoned the traditional accounting methods. In the ERP environment, accounting practitioners have added more ways to obtain information, which gives accountants more energy to improve themselves and accelerates the pace of innovation in the "Internet +" era.

\section{Introduction}

In modern enterprise management, ERP system optimizes enterprise resources and maximizes resource benefits at the same time. Under ERP environment, accounting information is the subversion of traditional accounting computerization mode. Which plays an important role in the allocation and optimization of resources and improves the operating efficiency of enterprises. ERP system is not an isolated system. There are many subsystems in it. The accounting information system discussed in this paper is one of them. At present, accounting information system has been well integrated into other subsystems of ERP system. In traditional enterprise management, the accounting method is based on each department of the enterprise. Each department shall present its own accounting information, and then the enterprise would conduct unified accounting. In the whole accounting process, accounting information is isolated. In the traditional accounting method, the information obtained by the accounting department may be incomplete, but these accounting information lacking authenticity and integrity will still be accounted for business operator. Enterprise decision makers are likely to make wrong decisions under the accounting information, which will damage the economic benefits of enterprises. Under ERP environment, the development of enterprise information will largely avoid these factors. ERP system enables the centralized sharing of information among various departments, so that enterprise resources can be used to the maximum extent. Figure 1 is the ERP system accounting information system flow chart 


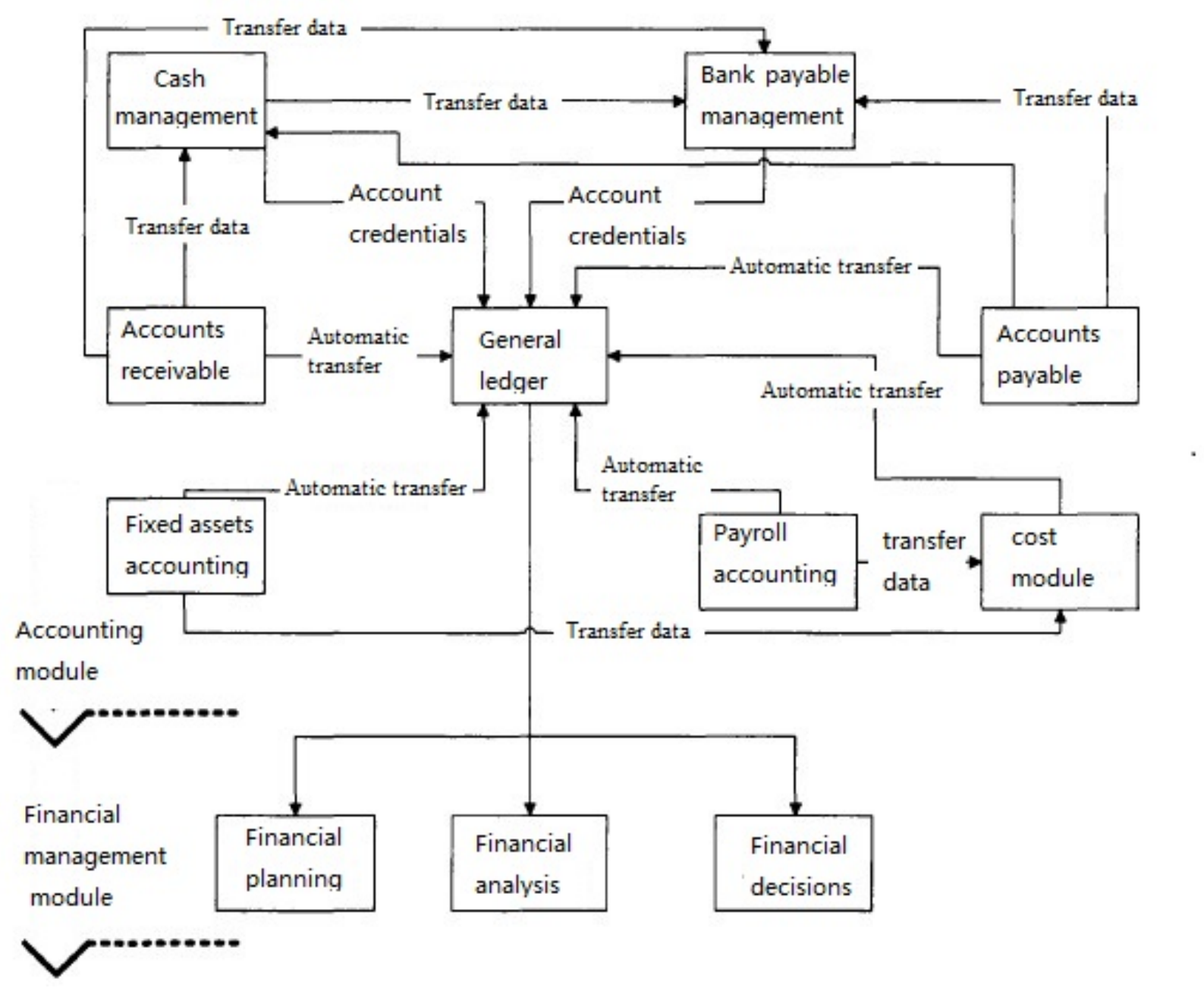

Figure 1 ERP system accounting information system flow chart

\section{The optimization of modern accounting information system}

\subsection{Optimize the scope: expand the target area of information collection}

Traditional accounting information system has many problems, such as small scope of information collection, the availability of accounting data, and so on. Nowadays, ERP system has been optimized for these limitations. The current ERP system will require users to record the accounting items, subjects, dates and places in a comprehensive and real way, which will realize the all-round management of accounting information more conveniently. Accounting department staff can communicate and automatically transfer accounting information through the Internet based on ERP system. Not only is this way faster, but the data is more realistic.

\subsection{Optimize the quality: improve the quality of input information}

ERP system stores the input information in the data server. When an enterprise department needs accounting information, this data server will select useful information and provides it to the user. In the early stage, the input information is required to be of high quality, so the information transmitted by the whole system is relatively accurate, which greatly improves the management level of the enterprise. 


\subsection{Optimize the efficiency: improve the collaboration efficiency}

ERP system can be used by every employee in the enterprise, so that employees can see the existing situation and avoid the waste of resources. The financial department can understand the business situation of other departments through the ERP system. They can detect and correct work errors in daily monitoring. This process greatly shortens the working time and improves the overall working efficiency.

\subsection{Optimize decision-making: promote the efficiency of financial decision-making}

After the original data input, ERP system will directly transfer and process the data into standard information. And then, they will prepare and report various financial statements of the enterprise based on the standard information. Compared with manual processing, ERP system shortens the accounting time and improves the accuracy of the results. Enterprise managers can directly analyze and make decisions on the financial statements, which greatly improves the efficiency and quality of financial decisions.

\subsection{Optimization processing: accounting information processing mode changes}

First, accounting vouchers are generated automatically through computer programs. In the ERP system, users can set the economic business to automatically generate credentials. Accountants just need to do a simple audit. Second, accounting information system can control the process of business processing. After the accounting staff of the enterprise collects the original information, ERP will process it automatically. Third, help business operators and managers to make financial decisions. At present, ERP system covers a wide range of areas. People can quickly and accurately collect the relevant financial information through the Internet, which is convenient for them to make decisions.

\subsection{Optimize the output: change the output mode of accounting information}

First, the output form of accounting information has become eclectic. After the integration of ERP system and Internet technology, the information transmission mode is not limited to written materials, but also can realize the information sharing of multiple enterprises. Second, diversified accounting information output content. With the development of international accounting information, accounting information system should keep pace with The Times. We can add more variety of content and modules. Only in this way can ERP system meet the diversified needs of different enterprises, industries, countries and markets. Accountants are responsible for recording economic operations and employee remuneration. In addition, they also provide real information to producers, managers, operators and investors of their own enterprises. In ERP system, accountants can provide users abundant information at one time. Which will help them draw conclusions more efficiently.

\section{Problems of accounting information in China}

\subsection{Poor internal control}

ERP system can not only promote the efficiency of enterprise management, but also increase the risk of enterprise financial management. ERP system information storage and processing is mainly concentrated in network system. This makes enterprises more vulnerable to network attack risk with 
poor security system, especially small and medium-sized enterprises.

\subsection{Poor accounting information management}

Enterprise management determines the level of accounting information management. Most enterprises are still in the closed management mode, accounting information is not open and transparent. Poor management will result in distortion of accounting information quality. In the process of accounting information, each department can operate and supervise the accounting work according to its own responsibilities.

\subsection{Lack of accounting information professionals}

There are many accountants in China, but few accountants are proficient in network information, which is an important factor hindering the development of accounting information. Therefore, the lack of comprehensive talents is the main factor hindering accounting information.

\section{Suggestions on improving the application of accounting information in China}

\subsection{Training comprehensive accounting information talents}

After enterprises adopt ERP system, the nature of accounting work has completed the transformation from data collection and accounting to system management. Which requires a comprehensive quality of accounting personnel. They should translate their thinking from accounting to management. Enterprises should carry out cross-process operation training, so that accountants are familiar with each business module. We also need to strengthen the training of each position, so that the enterprise finance, business, information and other departments make full use of ERP system functions. Which will better provide enterprise operators with high accuracy, strong correlation, reliable accounting information.

\subsection{Strengthening the supervision of accounting information system}

ERP system should disclose and supervise the quality of accounting information. Enterprises deeply understand the impact on the quality of accounting information. Enterprise supervisory and administrative organs need to update the inspection methods and inspection technology. The inspection management personnel should change the traditional inspection thinking mode and inspection operation method, which will be more suitable for the supervision and management of ERP system. Effective internal supervision and audit will improve the quality of accounting information and reduce the information asymmetry between enterprises and market investors. Good system is the guarantee of enterprise financial information security, which first needs to improve the risk awareness of accounting practitioners. There are three main types of risk, such as software vulnerability risk, internal staff leaks and poor network information security. So, improving ERP network system management can reduce enterprise risk.

\subsection{Strengthening the importance of raw financial data}

The raw data of production activity is the real reflection of enterprise operation. This is very important to enterprise financial accounting and management accounting, but also the basis of enterprise accounting information. Enterprise financial personnel should pay more attention to the original financial data and make registration and summary in each link. In the information input, we must formulate business norms to avoid negligence and omission. We can combine paper data with 
electronic data to improve the accuracy and security of information.

\section{Conclusions}

The implementation of accounting ERP system brings a lot of advantages. Such as. First, it improves the timeliness and accuracy of accounting data processing. Second, it solves the problem of information sharing between enterprise departments. Third, it strengthens the role of accounting supervision and management. Fourth, it promotes the updating of accounting techniques and theories. Fifth, it promotes the orderly development of enterprises. Which are the necessary trend of accounting information. Only by combining accounting work with ERP system can accounting work be planned, predicted and controlled.

\section{References}

[1] Robert L. Herter. Account Information Systems: Basic Concept \& Current Issues [M] , McGraw-Hill Press,2008.

[2] James Hill. Accounting Information System [M],2007.

[3] Anita S. Hollander, Eric L. Derma. Modern Accounting Information System [M],2005:p79-90

[4] Egelhoff, W. G. Information-Processing Theory and the Multinational Enterprise,-.Journal of International Business Studies [J], 2016, p341-68. 